\title{
Biomarkers development for early detection of cancer: Reducing the burden of cancer in the ageing society
}

\author{
Laura Paneghetti, Andrea Gallotta, Chiara Parrozzani and Giorgio Fassina*
}

\begin{abstract}
The ageing process in the European society will become one of the key driving forces of change over the next decades. The specific demands of older generations constitute a key market of the future, and the pressure to improve and expand health services increases, especially as far as chronic diseases, such as cancer. Availability of cost effective cancer early detection protocols, based on predictive biomarkers, will improve patients management reducing consequently the high costs associated to treating patients when the disease is at an advanced stage.
\end{abstract}

Keywords: biomarkers, cancer, health technology assessment (HTA), hepatocellular carcinoma, chronic hepatitis C, cirrhosis.

Xeptagen S.p.A., Via delle Industrie 9 30175 Venice, Italy

${ }^{*}$ Corresponding author: G. Fassina E-mail: fassina@xeptagen.com

DOI: 10.2478/ebtj-2018-0005

\section{Introduction}

Cancer is still a major cause of death worldwide, responsible for $15 \%$ of global deaths; AIDS, tuberculosis and malaria combined cause less casualties than tumors (1). In economically developed countries, cancer is second only to cardiovascular diseases as a leading cause of death, whereas in low- and middle-income countries it's in the third place (1). Recent data estimate more than eight million deaths/year caused by tumors (excluding non-melanoma skin cancers), of which 2.9 million in high-income countries (1).

The risk of developing cancer increases with age, and as the global average life expectancy raises, cancer incidence worldwide is incrementing (2). Due to the growth and aging of the world population, by 2030 the global burden of cancer is estimated to reach 22 million new cases and 13 million deaths (3). In high-income countries, which are characterised by an older population, $58 \%$ of newly diagnosed tumors arise in people $\geq 65$ years old (1).

Beside the human costs, cancer expenses are high also at the financial level: direct spending for diagnosis, treatment, care, and rehabilitation is added to the indirect costs for premature death and missed work (1). Although a precise number is unavailable, the estimated global annual expenditure associated with cancer is in the hundreds of billion dollars (1).

Early detection of cancer, before any symptoms emerge, is essential to get more effective treatments and better outcome, while saving costs for the national health systems (1). In this respect, biomarkers are incredibly valuable: non-invasive, safe, specific, reliable and cheap, they represent an ideal tool to screen, monitor, or diagnose diseases. Indeed, in recent years the development and validation of novel biomarkers has been a key aspect in new biotechnology products.

Tumour biomarkers may aid in early cancer detection and risk assessment; however, due to cancer heterogeneity, no single marker has shown to be fully satisfactory in terms of sensibility and specificity to be used for screening programs. Developing more accurate biomarkers and combining non overlapping biomarkers through dedicated algorithms 
to improve sensitivity and specificity for cost-effective clinical uses may represent a route to satisfy this still unmet medical need.

A novel source of biomarkers derives from the exploitation of the immune-surveillance against transformed malignant cells, since most, if not all, tumours are immunogenic. In many cancer biomarkers may be detected in the patients' sera as immune complexes. These biomarkers are formed by immunoglobulins-M bound with low affinity and high avidity to markers expressed during cancer (4). Occurrence of immune complexes has been reported in several cases: prostate specific antigen (PSA)-IgM in prostate cancer(5); carcinoembryonic antigen (CEA)-IgM in colon cancer(6); and squamous cell carcinoma antigen (SCCA)- $\operatorname{IgM}(7)$, alpha fetoprotein (AFP)- $\operatorname{IgM}(8)$ and des-gamma-carboxy prothrombin (DCP)- $\operatorname{IgM}(9)$ in liver cancer. Biomarker-IgM immune complexes have shown high diagnostic value, especially in early cancer detection, most likely because IgM antibodies act as "early birds" for the recognition and binding of abnormal antigens synthesized by the transformed cells.

In this context, the management of hepatocellular carcinoma (HCC) is particularly complicated, since no reliable biomarkers are available for early detection and treatment is difficult(10). In economically developed countries, most cases of HCC arise in patients with hepatitis $\mathrm{C}$ virus (HCV) and cirrhosis. Various studies have showed that HCV incidence in Western countries like the United States peaked in the years between 1970 and 1990, and the prevalence of HCV antibodies is at its highest in people born 1940-1960 (11). Thanks to the vaccination and screening methods applied over the past decades, HCV prevalence is projected to decline by half by 2030 (12). However, HCV liver disease progresses slowly over a long period of time; so, as $\mathrm{HCV}$-infected patients get older, in the coming 10-13 years there will be an increase in the prevalence of complication-related liver disease such as cirrhosis and HCC $(11,12)$.

As the people infected with HCV continue to age, it is critical to identify and treat liver disease as soon as possible: thanks to better treatment options available today, it is possible to modify the course of the disease before it progresses to an advanced stage, thus lowering the burden of HCV-related complications on national health systems and society (11). A growth in cancer cases as population's age should be anticipated and cancer early detection is getting increased attention to improve and expand health services. Innovative, efficient and cost effective screening devices for HCV patients to monitor risk of HCC development are urgently needed to improve quality of life.

\section{Novel monitoring models for early detection of $\mathrm{HCC}$ in $\mathrm{HCV}$ patients}

According to the World Health Organization, in order to help people maintain good and stable health for as long as possible, national health systems have to detect and control disease and risk factors early (13). When one disease is established and well-being starts to decline, health systems need to take action to minimize the effects of the illness. This means that, for a healthy aging, we need measures to prevent, cure or hinder disease (13).In regards to HCV and the subsequent cirrhosis, current European and American guidelines suggest a method of surveillance of cirrhotic patients at risk for HCC based on ultrasounds (US) performed every six months $(14,15)$. This method is cost-effective only when the annual incidence of HCC is equal or superior to $1,5 \%$ (15). Alternative monitoring systems based on biomarkers and selected sub-groups of patients could improve the cost-effectiveness and reduce the burden of liver disease on national health systems.

As mentioned above, SCCA-IgM has been validated by various clinical studies as a biomarker for liver diseases, including chronic hepatitis(16), cirrhosis, and $\operatorname{HCC}(7,17,18,19)$. SCCA-IgM can be used to monitor HCV patients with cirrhosis evolving to HCC: the biomarker increases over time in cirrhotic patients developing liver cancer, while it does not increase in patients without disease progression (17). Even at baseline, SCCA-IgM serological levels are significantly higher in patients who develop HCC than in those who do not develop cancer

Table 1. SCCA-IgM serological levels in patients with HCV infection and cirrhosis

\begin{tabular}{|c|c|c|c|c|c|c|c|}
\hline SCCA-IgM & DB 1 & DB 2 & DB 3 & DB 4 & DB 5 & DB 6 & TOT \\
\hline$\geq 0 \mathrm{AU} / \mathrm{mL}$ & $\begin{array}{c}272 \\
100 \%\end{array}$ & $\begin{array}{c}127 \\
100 \%\end{array}$ & $\begin{array}{c}67 \\
100 \%\end{array}$ & $\begin{array}{c}76 \\
100 \%\end{array}$ & $\begin{array}{c}24 \\
100 \%\end{array}$ & $\begin{array}{c}31 \\
100 \%\end{array}$ & $\begin{array}{c}597 \\
100 \%\end{array}$ \\
\hline$>50 \mathrm{AU} / \mathrm{mL}$ & $\begin{array}{l}206 \\
76 \%\end{array}$ & $\begin{array}{l}106 \\
84 \%\end{array}$ & $\begin{array}{c}61 \\
91 \%\end{array}$ & $\begin{array}{c}32 \\
42 \%\end{array}$ & $\begin{array}{c}22 \\
92 \%\end{array}$ & $\begin{array}{c}31 \\
100 \%\end{array}$ & $\begin{array}{l}458 \\
77 \%\end{array}$ \\
\hline$>200 \mathrm{AU} / \mathrm{mL}$ & $\begin{array}{l}121 \\
44 \%\end{array}$ & $\begin{array}{c}52 \\
41 \%\end{array}$ & $\begin{array}{c}29 \\
43 \%\end{array}$ & $\begin{array}{c}51 \\
67 \%\end{array}$ & $\begin{array}{c}7 \\
29 \%\end{array}$ & $\begin{array}{c}18 \\
58 \%\end{array}$ & $\begin{array}{l}278 \\
47 \%\end{array}$ \\
\hline$>300 \mathrm{AU} / \mathrm{mL}$ & $\begin{array}{c}88 \\
32 \%\end{array}$ & $\begin{array}{c}37 \\
29 \%\end{array}$ & $\begin{array}{c}20 \\
30 \%\end{array}$ & $\begin{array}{c}34 \\
45 \%\end{array}$ & $\begin{array}{c}7 \\
29 \%\end{array}$ & $\begin{array}{c}10 \\
32 \%\end{array}$ & $\begin{array}{l}196 \\
33 \%\end{array}$ \\
\hline$>500 \mathrm{AU} / \mathrm{mL}$ & $\begin{array}{c}67 \\
25 \%\end{array}$ & $\begin{array}{c}24 \\
19 \%\end{array}$ & $\begin{array}{c}16 \\
24 \%\end{array}$ & $\begin{array}{c}19 \\
25 \%\end{array}$ & $\begin{array}{c}5 \\
21 \%\end{array}$ & $\begin{array}{c}2 \\
7 \%\end{array}$ & $\begin{array}{l}133 \\
22 \%\end{array}$ \\
\hline$>600 \mathrm{AU} / \mathrm{mL}$ & $\begin{array}{c}60 \\
22 \%\end{array}$ & $\begin{array}{c}18 \\
14 \%\end{array}$ & $\begin{array}{c}13 \\
19 \%\end{array}$ & $\begin{array}{c}13 \\
17 \%\end{array}$ & $\begin{array}{c}3 \\
13 \%\end{array}$ & $\begin{array}{c}2 \\
7 \%\end{array}$ & $\begin{array}{c}109 \\
18 \%\end{array}$ \\
\hline
\end{tabular}


Table 2. SCCA-lgM levels and timing of HCC development in patients with HCV infection and cirrhosis

\begin{tabular}{|c|c|c|c|}
\hline SCCA-IgM & $\begin{array}{c}\text { HCC } 12 \\
\text { months } \\
\%\end{array}$ & $\begin{array}{c}\text { HCC } 6 \\
\text { months } \\
\%\end{array}$ & $\begin{array}{c}\text { HCC } 4 \\
\text { months } \\
\%\end{array}$ \\
\hline$\leq 50 \mathrm{AU} / \mathrm{mL}$ & $\begin{array}{c}0 / 16 \\
0 \%\end{array}$ & $\begin{array}{c}0 / 16 \\
0 \%\end{array}$ & $\begin{array}{c}0 / 16 \\
0 \%\end{array}$ \\
\hline$>50 \mathrm{AU} / \mathrm{mL}$ & $\begin{array}{c}24 / 287 \\
8,4 \%\end{array}$ & $\begin{array}{c}11 / 287 \\
3,8 \%\end{array}$ & $\begin{array}{c}10 / 287 \\
3,5 \%\end{array}$ \\
\hline$>500 \mathrm{AU} / \mathrm{mL}$ & $\begin{array}{c}7 / 63 \\
11,1 \%\end{array}$ & $\begin{array}{l}5 / 63 \\
7,9 \%\end{array}$ & $\begin{array}{l}5 / 63 \\
7,9 \%\end{array}$ \\
\hline
\end{tabular}

(18). Moreover, when HCC incidence is $3 \%$, the immune complex can identify HCV-infected cirrhotic patients with a negative predictive value (NPV) of $98,8 \%$ - that is, SCCA-IgM can identify patients with an extremely low risk of developing liver cancer during the following year (19).

Recently, an alternative model for monitoring HCV-cirrhotic patients has been developed: by quantifying the serological levels of SCCA-IgM, this model is able to identify different subgroups of patients in which semi-annual or annual US are more cost-effective.

Data from six separate studies performed on HCV-infected patients with cirrhosis show that SCCA-IgM is $>50 \mathrm{AU} / \mathrm{mL}$ in $77 \%$ of cases, $>200 \mathrm{AU} / \mathrm{mL}$ in almost half patients (47\%), $>300$ $\mathrm{AU} / \mathrm{mL}$ in one third of subjects (33\%) and $>500 \mathrm{AU} / \mathrm{mL}$ in $22 \%$ of patients. A smaller percentage of cases (18\%) has SCCA-IgM $>600 \mathrm{AU} / \mathrm{mL}$ (Table 1) $(18,19,20,21,22,23)$.

Three studies provide data on SCCA-IgM levels and timing of HCC development in patients with $\mathrm{HCV}$ infection and cirrhosis $(18,19,23)$ (Table 2): none of the subjects with SC$\mathrm{CA}-\operatorname{IgM} \leq 50 \mathrm{AU} / \mathrm{mL}$ develop liver cancer at four, six, or 12 months. Among the patients with SCCA-IgM $>50 \mathrm{AU} / \mathrm{mL}$, $8 \%$ have cancer after 12 months from the biomarker determination, $4 \%$ after six months, and 3,5\% after four months. The percentage of HCCs in subjects with SCCA-IgM $>500 \mathrm{AU} / \mathrm{mL}$ is higher: $11 \%$ of tumors developed in 12 months, $8 \%$ in six months, and another $8 \%$ in four months.

The analysis of the number of HCCs developed during the year following SCCA-IgM determination allowed the identification of a sub-group of HCV-cirrhotic patients at low risk for liver cancer. Indeed, all patients who develop HCC in 12 months have SCCA-IgM levels $>50 \mathrm{AU} / \mathrm{mL}$, while none of the subjects with lower levels of the biomarker develop HCC in the year after the analysis. Based on these observations, it can be concluded that patients with SCCA-IgM $\leq 50 \mathrm{AU} / \mathrm{mL}$ have a null risk for HCC development during the following year.

As mentioned earlier, the present method of surveillance based on ultrasounds (US) performed every six monthsis cost-effective when HCC annual incidence is $\geq 1,5 \%(15)$. According to the data described above, this type of surveillance is not cost-effective in HCV-cirrhotic patients with SCCA-IgM $\leq 50 \mathrm{AU} / \mathrm{mL}$, since in these subjects the incidence of liver cancer during the following 12 months is $0 \%$. Therefore, a new

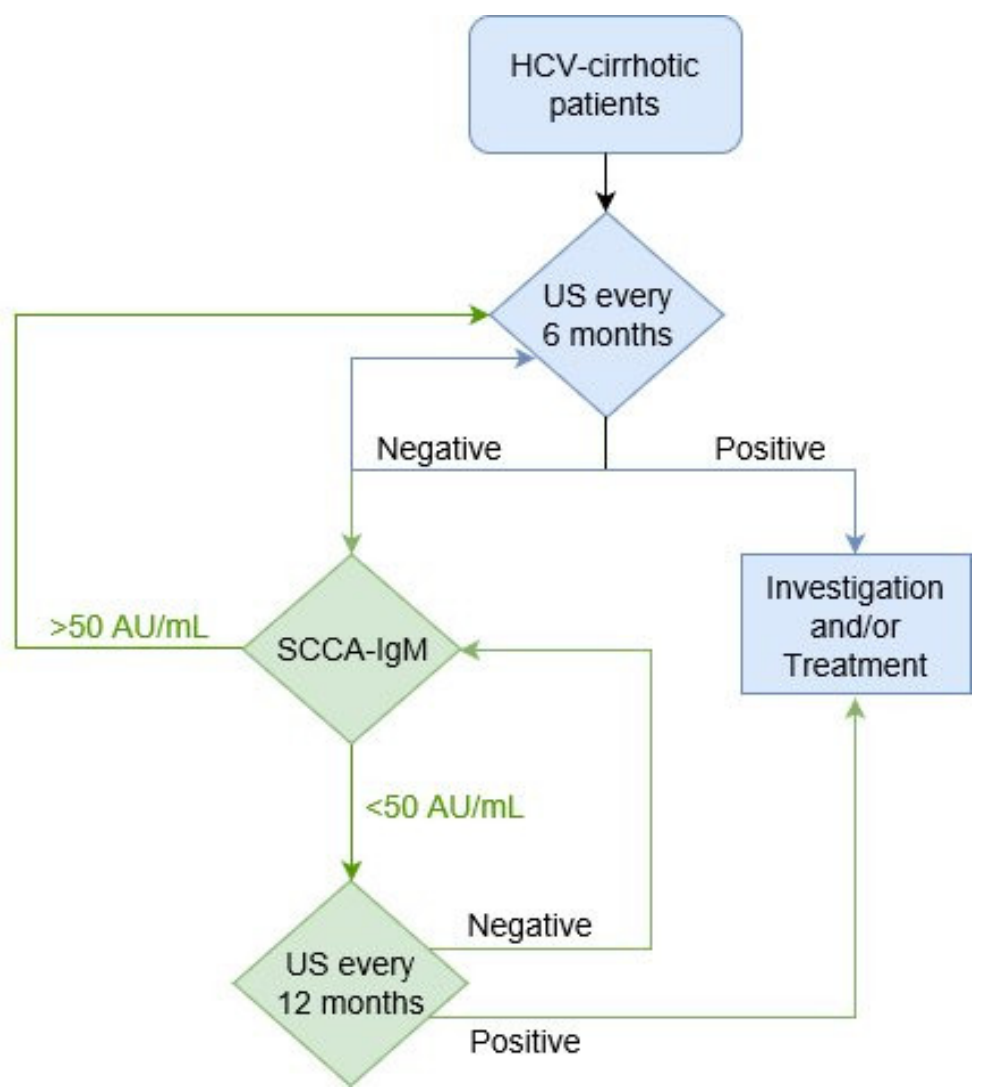

Figure 1. Monitoring of HCV-cirrhotic patients according to the current method (blue path) and the new alternative model (green path). 
Table 3. number of HCC and relative costs and savings associated with the monitoring of HCV-cirrhotic patients in Italy.

\begin{tabular}{|l|l|}
\hline $\begin{array}{l}\text { Annual cost of US only every } 6 \\
\text { months }\end{array}$ & $€ 46.516 .400$ \\
\hline $\begin{array}{l}\text { Annual cost of SCCA-IgM analysis } \\
\text { Costs saved by doing } 1 \text { US/year in- } \\
\text { stead of } 2\end{array}$ & $€ 4.008 .069$ \\
\hline Net costs of SCCA-IgM+US/year & $€ 45.276 .981$ \\
\hline $\begin{array}{l}\text { Annual saving of SCCA-IgM+US vs. US } \\
\text { only }\end{array}$ & $€ 1.239 .419$ \\
\hline HCC identified/year & $€ 11.974$ \\
\hline Cost of US only/HCC identified & $€ 3.885$ \\
\hline Cost of SCCA-IgM+US/HCC identified & $€ 3.781$ \\
\hline Saving/HCC identified & $€ 104$ \\
\hline
\end{tabular}

model to monitor HCV-infected cirrhotic patients has been developed: those with a negative US are tested for SCCA-IgM levels, and if the biomarker's concentration is $\leq 50 \mathrm{AU} / \mathrm{mL}$ the US is repeated after 12 months, instead of six (Fig. 1).

The model has been proved to be cost-effective when applied to the Italian population of cirrhotic patients. This analysis was based on an estimated cost of $€ 74$ for a liver US, and $€ 13$ for the determination of serological SCCA-IgM(24), while the number of cirrhotic patients in Italy was estimated to be around $314.300(25,26)$. With an annual HCC incidence of 5\% - which corresponds to $15.715 \mathrm{HCC} /$ year among the Italian cirrhotics -, and an average probability of 0,381 of identifying the cancer through US(27) - which results in 5.987 cases of HCC discovered at each US session in Italy-the analysis showed that current semi-annual monitoring of cirrhotic patients in Italy costs $€ 46.516 .400$ (=314.300 x €74 x 2) and finds a total of 11.974 positive US every year (=5.987 x 2) (Table 3 ).

By applying the new monitoring model, 308.313 cirrhotic patients have a negative result after the first US $(=314.300-$ 5.987) and are tested for SCCA-IgM levels, with an expenditure of $€ 4.008 .069$ ( $=€ 13 \times 308.313$ ) (Table 3). Based on the available data, $23 \%$ of patients - equivalent to 70.912 subjects - have SCCA-IgM levels $\leq 50 \mathrm{AU} / \mathrm{mL}$ and repeat the US after 12 months. This means that every year the Italian health system can save $€ 5.247 .488$ (=€74 x 70.912) (Table 3). Considering the extra expense for SCCA-IgM determination, the proposed model allows the Italian health system a net saving of $€ 1.239 .419 /$ year and of $€ 104 /$ HCC identified (Table 3).

\section{Conclusion}

Early detection of cancer can lower the ever increasing social burden associated with the management of patients with diseases at advanced stage, deriving by the failure of conventional diagnostic procedures or non adequateness for mass screening. Novel surveillance models tailored to sub-groups of patients selected through specific biomarkers represent promising alternative systems for monitoring patients at risk for cancer. For HCC in particular, current evidence show that novel monitoring models can save a lot of expenses to national health systems, with a very low risk of missing liver cancer cases, while also reducing the burden of US examinations in hospitals and clinics. This is an important aspect to consider as HCV-infected patients age and a high number of HCCs is expected in the coming years.

\section{References}

1. American Cancer Society, Global Cancer Facts \& Figures 3rd Edition. 2015, American Cancer Society: Atlanta.

2. National Cancer Institute. Probability of Developing or Dying of Cancer. 2015 [cited 2016] ; Available from: srab.cancer.gov/devcan.

3. Bray F, Jemal A, Grey N, Ferlay J, Forman D. Global cancer transitions according to the Human Development Index (2008-2030): a population-based study. Lancet Oncology. 2012. 13: 790-801.

4. Vollmers HP, Brandlein S. Natural antibodies and cancer. Journal of Autoimmunity. 2007. 29(4): 295-302.

5. Beneduce L, Prayer-Galletti T, Marcello Grimani Giustinian A, Gallotta A, Betto G, Pagano F, Fassina G. Detection of prostate specific antigen coupled to immunoglobulin $\mathrm{M}$ In prostate cancer patients. Cancer Detection and Prevention. 2007. 31: 402-407.

6. Castaldi F, Marino M, Beneduce L, Belluco C, De Marchi F, Mammano $E$, Nitti D, Lise M, Fassina G. Detection of circulating CEA-lgM complexes in early stage colorectal cancer. International Journal of Biological Markers. 2005. 20(4): 204-208.

7. Beneduce L, Castaldi F, Marino M, Quarta S, Ruvoletto M, Benvegnù L, Calabrese F, Gatta A, Pontisso P, Fassina G. Squamous cell carcinoma antigen-Immunoglobulin $\mathrm{M}$ complexes as novel biomarkers for hepatocellular carcinoma. Cancer. 2005. 103: 2558-2565.

8. Beneduce L, Castaldi F, Marino M, Tono N, Gatta A, Pontisso P, Fassina G. Improvement of liver cancer detection with simultaneous assessment of circulating levels of free alpha-fetoprotein (AFP) and AFP-IgM complexes. International Journal of Biological Markers. 2004. 19: 155-159.

9. Beneduce L, Pesce G, Gallotta A, Zampieri F, Biasiolo A, Tono N, Boscato N, Gatta A, Pontisso P, Fassina G. Tumour-specific induction of immune complexes: DCP-lgM in hepatocellular carcinoma. European Journal of Clinical Investigation. 2008. 38: 571-577.

10. Martini A, Gallotta A, Pontisso P, Fassina G. Clinical applications of squamous cell carcinoma antigen_immunoglobulins $M$ to monitor chronic hepatitis C. World Journal of Hepatology. 2015. 7(29): 2913-2919.

11. Biggins SW, Bambha KM, Terrault NA, Inadomi J, Shiboski S, Dodge JL, Gralla J, Rosen HR, Roberts JP. Projected future increase in aging hepatitis $C$ virus-infected liver transplant candidates: a potential effect of hepatocellular carcinoma. Liver Transplantation. 2012. 18: 1471-1478.

12. Davis GL, Alter MJ, El-Serag H, Poynard T, Jennings LW. Aging of hepatitis $C$ virus (HCV)-infected persons in the United States: a multiple cohort model of HCV prevalence and disease progression. Gastroenterology. 2010. 138: 513-521.

13. World Health Organization, World report on aging and health. 2015.

14. EASL-EORTC. Clinical practice guidelines: management of hepatocellular carcinoma. Journal of Hepatology. 2012. 56: 908-943.

15. Bruix J,Sherman M. Management of hepatocellular carcinoma: an update. Hepatology. 2011. 53(3): 1020-1022.

16. Biasiolo A, Chemello L, Quarta S, Cavalletto L, Bortolotti F, Caberlotto C, Beneduce L, Bernardinello E, Tono N, Fassina G, Gatta A, 
Pontisso P. Monitoring SCCA-IgM complexes in serum predicts liver disease progression in patients with chronic hepatitis. Journal of Viral Hepatitis. 2008. 15: 246-249.

17. Pontisso P,Quarta S, Caberlotto C, Beneduce L, Marino M, Bernardinello E, Tono N, Fassina G, Cavalletto L, Gatta A, Chemello L. Progressive increse of SCCA-IgM immune complexes in cirrhotic patients is associated with development of hepatocellular carcinoma. International Journal of Cancer. 2006. 119: 735-740.

18. Biasiolo A, Trotta E, Fasolato S, Ruvoletto M, Martini A, Gallotta A, Fassina G, Angeli P, Gatta A, Pontisso P. Squamous cell carcinoma antigen-IgM is associated with hepatocellular carcinoma in patients with cirrhosis: A prospective study.Digestive Liver Disease. 2016. 48(2): 197-202.

19. Buccione D, Fatti G, Gallotta A, Loggi E, Di Donato R, Testa L, Saitta C, Santi V, Di Micoli A, Erroi V, Frigerio M, Fazio V, Picciotto A, Biasiolo A, Degos F, Pontisso P, Raimondo G, Trevisani F. Serum SCCA-IgM as a predictor of hepatocellular carcinoma in patients with cirrhosis. Open Journal of Gastroenterology. 2012. 2: 56-61.

20. Morisco F,Guarino M, Di Costanzo GG, Gallotta A, Fassina G, Tortora R, Tuccillo C, Granata R, Loperto I, Auriemma F, Caporaso N. Circulating SCCA-IgM complex is a useful biomarker to predict the outcome of therapy in HCC patients. Journal of Hepatology. 2015. 62(S450).

21. Giannelli G, Fransvea E, Trerotoli P, Beaugrand M, Marinosci F, Lupo L, Nkontchou G, Dentico P, Antonaci S. Clinical validation of com- bined serological biomarkers for improved hepatocellular carcinoma diagnosis in 961 patients. Clinica Chimica Acta. 2007. 383: 147-152.

22. Crescenzi M, Tessari A, Biasiolo A, Padoan A, Gallotta A, Fassina G, Panciatichi C, Rossetto O, Pontisso P, Basso D, Plebani M. Analytical Validation of a biochip prototype for integrated analysis of AFP$\operatorname{lgM}$ and SCCA-IgM serum biomarkers in patients with liver cirrhosis and hepatocellular carcinoma.Analytical Methods. 2015(2): 626-637.

23. Gil-Gómez A, Ampuero J, Gallego-Durán R, Fassina G, Pontisso P, Romero-Gomez M. SCCA-IgM helps to identify patients at risk of long-term hepatocellular carcinoma.Hepatology. 2016. 64(S1): 656A.

24. Regione Veneto. Tariffario delle Prestazioni Specialistiche Ambulatoriali.

25. AIRTUM-AIOM, I numeri del cancro in Italia. 2016.

26. Giannini EG,Cucchetti A, Erroi V, Garuti F, Odaldi F, Trevisani F. Surveillance for early diagnosis of hepatocellular carcinoma: how best to do it? World Journal of Gastroenterology. 2013. 19(47): 8808-8821.

27. Thompson Coon J,Rogers G, Hewson P, Wright D, Anderson R, Jackson S, Ryder S, Cramp M, Stein K. Surveillance of cirrhosis for hepatocellular carcinoma: a cost-utility analysis. British Journal of Cancer. 2008. 98: 1166-1175. 